\title{
Literacy Instruction In The Mother Tongue: The Case Of Pupils Using Mixed Vocabularies
}

Alma Sonia Q. Sanchez, Leyte Normal University, Philippines

\begin{abstract}
In the institutionalization of the mother tongue-based multilingual education (MTB-MLE) in the country, several trainings were conducted introducing its unique features such as the use of the two-track method in teaching reading based on the frequency of the sounds of the first language (L1). This study attempted to find out how the accuracy track method worked with Waray pupils using mixed vocabularies. This is a part of a developmental study that aims to improve Waray reading instruction in basic education. The researcher used a checklist of the 100 Most Common Words in Waray for pretest and posttest, interviews, survey questionnaires, and daily observations during the three-week implementation of the method. The averages of the pretest and posttest scores were compared. Themes and patterns in the responses were likewise analyzed. The results showed a big gap in the performance of pupils classified as readers and beginning readers. Several issues and challenges met were also identified. These imply that the method is less facilitative for effective teaching and learning in Waray of speakers using mixed vocabularies. This study recommends to modify the method or to develop an appropriate method for literacy instruction of speakers without a strong linguistic foundation in their mother tongue.
\end{abstract}

Keywords: Mother Tongue Literacy Instruction; Multilingual Education; Mixed Vocabularies

\section{INTRODUCTION}

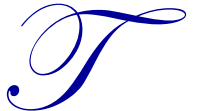

he use of mother tongue provides children with an equitable opportunity to access and facilitate learning. Studies assert that the use of a child's home language is one of the most important factors in helping children learn to read and write and in learning academic content and other languages. Defined as one's first language, home language, and heritage language (Malone, 2004), mother tongue is considered as a language one knows best apt for use in beginning education. Claiming that children develop new knowledge and skills based on what they already know from their community and culture (Dekker, 2003), primary education programs that begin in children's mother tongue are believed to help students gain early reading skills more quickly, as well as transfer key skills to a second or a third language.

In the study of Krashen (2001), he provides that what the theory implies is that first or second language acquisition occurs when comprehension of real messages occurs. Language acquisition does not require extensive use of conscious grammatical rules and does not require tedious skills. Thus, there is emphasis on meaning and communication (focusing on whole texts) and on accuracy and correctness (focusing on parts of the language) (Malone, 2004). In assessing learning, studies of Cummins (2000) and Thomas and Collier (1997) claim that the level of development of children's mother tongue is a strong predictor of their second language development. Cummins (2000) found that children with a solid foundation in their mother tongue develop stronger literacy abilities in the school language which enable them to go from the known to the unknown using what they have learned about reading and writing in the first language and their knowledge of oral second language to bridge into reading and writing the second language. This was supported by the study of Thomas and Collier (1997) noting that only those language minority students who had five to six years of strong cognitive and academic development through their first language as well as through their second language did well in Grade 11 assessments building a good bridge to the new language(s), beginning with listening, speaking, reading, and writing. 
The mother tongue-based and multilingual education's case is therefore simple: Children learn best in a language that is familiar to them. However, Waray children in the Philippines are found to have gaps in their mother tongue. In a study conducted by Caspe, C., Oyzon, V., Ripalda, L., \& Salamia, J. (2012), Waray educands of today were described to be more familiar with English vocabulary than the indigenous Waray terms while Oyzon (2010) observed Waray children to unconsciously shift from their mother language to English or Tagalog in their vocabulary use. For instance, in a classroom set-up, a picture can be identified easily as sun rather than the Waray equivalent term adlaw or cloud rather than dampog.

Several teacher-trainings for the implementation of Department of Education (DepEd) Order No. 74, s. 2009, which institutionalized mother tongue-based multilingual education (MTB-MLE) in the country had been conducted. These trainings covered four-fold topics focusing on the theoretical and pedagogical foundations of MTB-MLE, materials development, and awareness building. As a unique feature of MTB-MLE, the trainings stressed the use of the two-track method as a teaching strategy in reading using the mother tongue.

However, this method and findings of studies rest on the assumption that the children have strong linguistic foundation in their first language. As far as this study is concerned, no study has been made on how the mother tongue accuracy track method works in teaching reading to pupils using mixed vocabularies in the Waray region of the Philippines. It is based on this framework that the present study was conducted. This study specifically tried to examine the changes in the reading performance of the pupils, the advantages, and the challenges and issues met by the pupils and the classroom teacher in using the method.

\section{MATERIALS AND METHODS}

\section{Design}

The foregoing is a part of a developmental study that aims to improve Waray reading instruction in basic education, specifically the primary level. The researcher used the descriptive case study design as described by Baxter P. \& Jack S. (2008) using a variety of data sources to describe the implementation of the accuracy track method and the real-life context in which it occurred.

\section{Respondents}

Thirty-seven 5 to 7 year old grade one pupils of Leyte Normal University- Integrated Laboratory School (LNU-ILS) participated in this study. Twenty-six of them were enrolled in the Kindergarten MTB program of the university while 11 came from private schools following the English-based curriculum. In a previous survey conducted to verify the language used by the pupils, the researcher found that $83.78 \%$ ( 31 pupils) of the class use a combination of Waray, Filipino, and English in conversations at home, 13.51\% (5 pupils) use only Waray, while only $2.7 \%$ ( 1 pupil) is exposed to pure English at home. However, 100\% of the class (37 pupils) use a combination of Waray, Filipino, and English in conversations with peers and classmates. Though the results of the survey speak that there was preference in the use of English vocabulary, recorded conversations and observations confirm Young's (2000) findings that Filipino children's mother tongue is neither Filipino nor English. Though there are borrowed foreign terms, the respondents' medium of communication is still Waray.

\section{The Primer and its Implementation}

A Waray primer using the accuracy track in the MTB two-track method was used in teaching reading. The two-track method makes use of two simultaneous 'tracks' of literacy instruction; one focusing on meaning and the other on accuracy. The accuracy track is a phonics based approach following the processes of doing a symbol count (frequency count), planning the order of the letter lessons, choosing key words for the lessons, and identifying words for sentence-making activities. Specific rules are followed in identifying key words to introduce the symbols. These rules outlined in the study of Malone (2010) include the introduction of only one new symbol in a lesson, the use of familiar key pictures and short keywords which preferably have the new symbol at the beginning of the word or at the beginning of a syllable clearly represented by a picture. 
The researcher did a frequency count using three contemporary Waray short stories. From the input texts, the most frequent sounds in Waray appeared in this order: $/ \mathrm{a} / / \mathrm{i} / \mathrm{h} /$ for the vowel sounds and $/ \mathrm{n}, / \mathrm{h}, / \mathrm{k}, / \mathrm{t}, / \mathrm{ng}, / \mathrm{m}$, $/ \mathrm{g}, / \mathrm{r}, / \mathrm{y}, / \mathrm{p}, / \mathrm{s}, / \mathrm{l}, / \mathrm{d}, / \mathrm{b}, / \mathrm{w} /$ for the consonant sounds with borrowed sounds /e, /o, /c, /f, /j, /q, /ñ, /v, /x, and /z/. Lessons were patterned according to the frequency order of sounds starting with the introduction of the vowel sounds followed by the consonant sounds. Identified readers of the class were given short Waray reading texts while others used the accuracy track method in reading.

\section{Instrument}

A pretest/posttest using a checklist of the 100 Most Common Words in Waray taken from the First 500 Commonly Used Words in Waray in the study conducted by Oyzon (2012) was used to determine the reading proficiency of the children.

\section{Data Analysis}

A methodological triangulation as described by Diehl, D., Guion, L., \& McDonald, D. (2011) involving the qualitative and quantitative methods in the study was used. From the results of the pretest, the respondents were divided into three (3) groups: Group A for those who got a perfect score, Group B for those who got scores from 199, and Group C for those who got a zero score. A posttest was given after three weeks of implementation. The pretest/posttest mean scores were compared. Themes and patterns in the responses and behaviors during the interviews and direct observations were recorded and tabulated to determine how respondents find instruction in the mother tongue. Individual and group interviews were conducted as the need arose to verify and confirm responses and explanations

\section{RESULTS AND DISCUSSION}

\section{Reading Performance Before and After Exposure to the Method}

The pretest scores of the respondents got a mean value of 20.49 while the posttest scores got 30.14 showing a mean gain of 9.65. Group B composed of seven respondents improved their scores from 36-97 to 93-100 with a mean gain of 32.57 from the mean score of 65.43 in the pretest to 98.00 in the posttest. The 27 respondents in Group $\mathrm{C}$ who got zero in the pretest got a mean score of 4.7 in the posttest scores. Twelve out of the 27 pupils in Group C were consistently zero in the pretest and posttest. The other 15 respondents under the same group improved with scores ranging from 1-27 which is still below the targeted proficiency level of 75 points. The number of pupils who reached the $75 \%$ targeted proficiency level increased from four respondents in the pretest to 10 respondents in the posttest. Thus, only $27.03 \%$ of the class passed after the implementation of the method.

\section{Advantages of the MTB-MLE Accuracy Track Method}

The concept of introducing one symbol at a time worked. The respondents had less difficulty mastering one new symbol and sound at a time and even in combining the new sound with other previously learned sounds. Lessons do not seem heavy and the classroom was less threatening since pupils were not bombarded with new things all at once.

In the interviews conducted, responses supported the studies (Arzadon, 2010; Azurin, 2010 \& Walter, 1991) asserting the positive effects of using the first language in instruction. Respondents claimed that they gained more confidence in reciting. Furthermore, the researcher observed that almost everyone wanted to share their experiences in class.

\section{Challenges and Issues in the Implementation of the Method}

All throughout the sessions, the researcher struggled looking for key words following the order of sound combinations only to teach by syllabic patterns when respondents failed to recognize the clues. Though there were 10 identified readers in class, the researcher observed that they use syllabic reading and could hardly associate some 
words with the key pictures. In some sessions, the respondents did not understand the keywords and were not able to give the equivalent term of the key pictures in Waray. An example is when instead of identifying the key picture as bukad, the speaker calls it flower, instead of bunay, it is called itlog (egg).

On the other hand, the low scores of the beginning readers were concurring with their recorded difficulties. When presented with a characteristically long Waray word (Oyzon, 2010), 72.97\% of the class (27 pupils in Group C) would cover the words exposing one syllable after another in reading. For instance, they concealed the Waray word uhataw (bowl) with their hands or with a cardboard and revealed the word by syllable either in the pattern: $u$, ha, taw $=$ uhataw or $u$, uha, uhataw. Recorded observations of this group also showed that though they have mastered the new sound introduced like $/ \mathrm{n} /$ in the $/ \mathrm{n} /$ and vowel combinations or the sound $/ \mathrm{h} / \mathrm{in} \mathrm{the} / \mathrm{n} / / \mathrm{h} /$, and vowel combinations, 59. 26\% (16 pupils) got confused when the words given had a combination of vowels or series of vowel sounds such as reading nauna (went ahead) as nana or nawna and hain (where) as hin, han or hani. Same was true with words having consonant-vowel-consonant (CVC) syllables at the middle or last part of the word like tikadto (on the way to) and dasag (square). $48.15 \%$ (13 pupils) omitted the last consonant sound of the syllable and read the words as tikato and dasa, not being used to syllabic reading. There were also $51.85 \%$ (14 pupils) who were fond of adding vowel sounds in reading words ending with a consonant sound like reading gamit (thing) as gamita found to be attributed to the heavy pronunciation of sounds in the Waray language and an erroneous prior teaching of sounds. The 12 pupils from this group who were consistently zero in their pretest and posttest scores were found to have a combination of all the listed difficulties. Furthermore, $100 \%$ of the class guessed the key pictures at one point using either English or Filipino language in the process such as the answer "Maaram ak hito. Dog ito." (I know that. That is a dog.) instead of saying ayam or ido demonstrating their preferred language for the key pictures.

\section{IMPLICATIONS}

Challenges were encountered in the implementation of the accuracy track method with this type of students. This can be attributed to the fact that the MTB methods introduced work best on children with strong linguistic foundation in the first language such as in the studies of Cummins (2000), Dekker (2003) \& Malone (2004). The big gap in the performance of pupils identified to be readers and beginning readers shows that the method is less facilitative for effective teaching and learning of Waray speakers using mixed vocabularies. Though readers of the class were able to read more words, some beginning readers were still consistently zero implying that they have difficulty learning to read using the method

Since the task in MTBMLE is to save [a marginalized] language and to support the rebuilding of the vocabulary in one's own language (Arzadon, 2010), Waray literacy instruction should be strengthened using an approach geared to address the needs of these speakers. The study therefore recommends to modify the accuracy track method or to develop an appropriate method for literacy instruction of Waray speakers without a strong linguistic foundation in the mother tongue. In view of the fact that the accuracy-track method uses keywords and key pictures in the mother tongue which may still be unfamiliar to this group of speakers, it is suggested to defer the use of pictures at the early stage of instruction. Given that purpose of teaching with meaning can hardly be achieved in a group that does not recognize the meaning of words, teaching with the use of keywords may be introduced at the later part of the instruction for beginning readers. Instead, teaching by syllables should be emphasized based on the syllabic pattern of Waray language which is consonant-vowel (CV) or consonant-vowel-consonant (CVC) (Nolasco, M.R.D., Oyzon, V.Q., \& Ramos, F.J., 2012). For maximized learning, pupils should move in a ladderlike manner following the order of frequency of Waray sounds. A perfect score for each stage should be required before a pupil can move to the next stage. In this case, studies in applying cross-age tutoring or peer-tutoring strategy are needed to assist the teacher in the classroom. It is also recommended that the same study be conducted in other schools with similar set-up to verify the results. The time for implementation may be lengthened as well. For comparison, a study on the effects of modifying the primer accuracy track method is likewise recommended.

\section{ACKNOWLEDGMENTS}

This paper was written with the support and inspiration of Mr. Ian Phil M. Canlas, Mr. Ariel G. Salarda, Mr. Voltaire Q. Oyzon, Miss Cyrene Caspe, the LNU-ILS faculty, the ILS practice teachers for SY 2012-2013, and the LNU Research Council. 


\section{AUTHOR INFORMATION}

Alma Sonia Quiero Sanchez has completed BEED-BSED English and MAED Montessori Education. She is an instructor of the Leyte Normal University in Tacloban City, Philippines assigned as a Supervising Teacher Educator (STE) of practice teachers at the Integrated Laboratory School under the College of Education. Currently, she is an STE at the Grade 1 class implementing the mother tongue-based instruction. She has participated in national and regional mother tongue-based multilingual education (MTBMLE) conferences and trainers' training and is one of the resource speakers for MTB-MLE implementation in the Waray region.

E-mail: alexnightingale2000@yahoo.com

\section{REFERENCES}

1. Arzadon, C. (2010). Dedicated to cause greater than themselves. In Nolasco, R.M.D., Datar, F.A., \& Azurin A.M., (Eds.), Starting Where the Children Are: A Collection of Essays on Mother Tongue-Based Multilingual Education and Language Issues in the Philippines, Quezon City: 170+ Talaytayan MLE Inc., 12-17.

2. Abuyen, T. A. (2005). Dictionary English Waray-Waray/Tagalog. National Book Store, 494 pp., ISBN 971-08-6529-3. Retrieved from http://en.wikipedia.org/wiki/Special:BookSources/9710865293

3. Azurin, A. M. (2010). Reinventing basic education: the shift to mother tongue-based instruction. In Nolasco, R.M.D., Datar, F.A., \& Azurin A.M., (Eds.), Starting Where the Children Are: A Collection of Essays on Mother Tongue-Based Multilingual Education and Language Issues in the Philippines, Quezon City: 170+ Talaytayan MLE Inc., 1-6.

4. Baxter P. \& Jack S. (2008). Qualitative Case Study Methodology: Study Design and Implementation for Novice Researchers. The Qualitative Report, Volume 13 Number 4, 544-559. Retrieved from http://www.nova.edu/ssss/QR/QR13-4/baxter.pdf

5. $\quad$ Caspe, C., Oyzon, V., Ripalda, L., \& Salamia, J. (2012). Teaching Geometrical Figures in Waray: The LNU-ILS Experience, a paper read in the 2nd Philippine Conference-Workshop on MTBMLE, Punta Villa Resort, Arevalo, Iloilo City, February 16-18, 2012.

6. Cummins, Jim (2000). Bilingual children's mother tongue: Why is it important for education? Sprogforum Nr. 19, 2001, 15-20. Retrieved from http://www.iteachilearn.com/cummins/mother.htm

7. Dekker, D. E. (2003). A case study of the first language component bridging program in rural Philippines. Philippine Journal of Linguistics, 143-149.

8. Diehl, D., Guion, L. and McDonald, D. (2011). Triangulation: Establishing the Validity of Qualitative Studies. University of Florida; Gainesville, FL 32611. Retrieved from http://edis.ifas.ufl.edu

9. Department of Education Order No. 18, s. 2011. Guidelines on the Conduct of Mother Tongue-Based Multilingual Education Training. Retrieved from http://www.deped.gov.ph/cpanel/uploads/issuanceImg/DepED\%202011new.pdf

10. Department of Education Order No. 74, s. 2009. Retrieved from http://www.deped.gov.ph/cpanel/uploads/issuanceImg/DO\%20No.\%2074,\%20s.\%202009.pdf

11. Espada, Janet E. (2012). The Native Language in Teaching Kindergarten Mathematics. Journal of International Education Research, $4^{\text {th }}$ Quarter, 359-366.

12. Krashen, Stephen D. (2001). Principles and Practice in Second Language Acquisition. English Language Teaching Series. London: Prentice-Hall International (UK) Ltd (2001). Retrieved from http://www.languageimpact.com/articles/rw/krashenbk.htm. p. 6-7

13. Malone, Susan E. (2004). Programs in Minority Language Communities: Resource manual for speakers of minority languages engaged in planning and implementing mother tongue-based education programs in their own communities. UNESCO Bangkok, 2004. Retrieved from http://www.sil.org/acpub/repository/MLE\%20Program\%20Planning\%20manual.pdf

14. Malone, Susan E. (2010). Guide to Developing a "Sounds of our Language" Book for teachers to use in the 2-track method-Accuracy Track. Adapted from "The Sounds of Your Language" Published 1991, by the Department of Education, Papua New Guinea. Written by R. Litteral and S. Malone. ISBN 9980-58-659-1 Retrieved from http://www.sil.org/acpub/repository/Guide\%20to\%20developing\%20a\%20primer\%20for\%202track\%20method.pdf 
15. Nolasco, M.R.D., Oyzon, V.Q., \& Ramos, F.J. (2012). An Bag-o nga Ortograpiya han Winaray. Panrehiyong Sentro sa Wikang Filipino-R8, Leyte Normal University, Tacloban City, Philippines.

16. Oyzon, V. (2010). Taking Another Woman as My Mother: The State of Waray Language as Used by Today's Waray Children, a paper read in the 1st Philippine Conference on Mother Tongue-Based Multilingual Education, Capitol University, Cagayan de Oro City, February 18-20, 2010.

17. Oyzon, V.Q. (2012). The 500 Most Common Words in Waray. Panrehiyong Sentro sa Wikang Filipino-R8, Leyte Normal University, Tacloban City, Philippines.

18. Thomas, W. P. \& Collier, V.P. (1997). School effectiveness for language minority students. Retrieved from http://www.ncela.gwu.edu/ncbepubs/resource/effectiveness/

19. Walter, G.S. (1991). Degree of bilingualism and arithmetic problem solving in Hispanic first graders. The Elementary School Journal, 92 (2), 213-231.

20. Young, C. (2003). First language: A foundation for effective basic education. Philippine Journal of Linguistics, 34 (1), 123-131. 